\title{
Radio(chemoltherapy in locally advanced nonsmall cell lung cancer
}

\author{
Markus Glatzer ${ }^{1}$, Olgun Elicin ${ }^{2}$, Sara Ramella ${ }^{3}$, Ursula Nestle ${ }^{4,5}$ and \\ Paul Martin Putora ${ }^{1}$
}

Affiliations: ${ }^{1}$ Dept of Radiation Oncology, Kantonsspital St. Gallen, St. Gallen, Switzerland. ${ }^{2}$ Dept of Radiation Oncology, University Hospital Bern, Bern, Switzerland. ${ }^{3}$ Dept of Radiation Oncology, Campus Bio-Medico University, Rome, Italy. ${ }^{4}$ Dept of Radiation Oncology, University Medical Center Freiburg, Freiburg, Germany. ${ }^{5}$ German Cancer Consortium (DKTK), Heidelberg, Germany.

Correspondence: Paul Martin Putora, Dept of Radiation Oncology, Kantonsspital St. Gallen, Rorschacherstrasse 95, 9007 St. Gallen, Switzerland. E-mail: paul.putoraakssg.ch

ABSTRACT Definitive radiochemotherapy is the standard treatment for many patients with locally advanced nonsmall cell lung cancer (NSCLC). Treatment outcomes have improved over the last decades. Several treatment regimens have been shown effective and safe. This review summarises the results of significant studies between 1996 and 2015 on concomitant and sequential radiochemotherapy regimens and radiation dose per fraction. Beside therapy regimens, optimised radiotherapy planning is indispensable to improve outcome and minimise radiation-induced toxicity. An insight into the rationale of radiotherapy planning for stage III NSCLC is also provided.

0

@ERSpublications

Concomitant radiochemotherapy is an established standard treatment for locally advanced nonsmall cell lung cancer http://ow.ly/TTkkc

\section{Introduction}

Radio(chemo)therapy has been an important part of lung cancer treatment for several decades and its recent advances have led to significant improvements in treatment outcomes. The current review will focus on the application of radiotherapy for locally advanced nonsmall cell lung cancer (NSCLC).

Lung cancer is one of the most common causes of cancer death, with many patients diagnosed in a locally advanced stage. Although the treatment outcome has improved over the last decades, it remains poor [1].

Locally advanced lung cancer is a heterogeneous group and the definition often overlaps with stage III lung cancer. Typically patients with stage I/II lung cancer would be primarily considered for curatively intended surgery or stereotactic body radiotherapy in case of inoperability. Stage IV patients would typically receive palliative treatment [2], often involving systemic agents while nowadays multimodal concepts are being tested in oligo-metastatic cases.

\section{Staging}

An essential part of lung cancer staging is proper mediastinal lymph node staging, which may be achieved by fine needle aspiration (e.g. endobronchial ultrasound guided biopsies, transoesophageal biopsies), mediastinoscopy, 18-fluorodeoxyglucose positron emission tomography or a combination of these. When mediastinal lymph nodes are limited to the ipsilateral mediastinum, it is considered N2 (stage IIIA: T1-3 $\mathrm{N} 2$ or T4 N1) disease, while contralateral involvement denotes N3 disease (stage IIIB: T1-3 N3 or T4 N2). While stage IIIB N3 is generally not amenable to surgery [3], certain subsets of stage IIIA N2 disease are approachable with surgery. To help differentiate, the American College of Chest Physicians has published

Received: July 032015 | Accepted after revision: July 232015

Conflict of interest: None declared.

Provenance: Submitted article, peer reviewed.

Copyright OERS 2016. ERR articles are open access and distributed under the terms of the Creative Commons Attribution Non-Commercial Licence 4.0. 
a sub-classification of N2 disease [4]. Typically bulky and/or multi-level N2 disease is associated with a high rate of micro-metastatic spread and extensive mediastinal involvement. In this setting as well as in stage IIIB, definitive radio-chemotherapy is the standard treatment.

\section{Radiotherapy alone}

Radiotherapy delivers ionising radiation, which in turn causes physical and chemical interactions leading to DNA and other tumour damage. Repetitive exposure to appropriate doses of radiation causes increased damage to tumour cells when compared to healthy tissue. This is the basis of conventionally fractionated radiotherapy, where typically a dose of $2 \mathrm{~Gy}$ is delivered five times per week.

Currently a daily fraction of 1.8-2 Gy is considered standard for lung cancer. Alternative dose-fractionation schedules have been investigated, especially for patients who are not suitable for concurrent chemotherapy. Several clinical trials in the last two decades show a survival benefit of hyperfractionated radiotherapy (twice or three times a day with doses $<1.8 \mathrm{~Gy}$ ) over conventional fractionation $[5,6]$. However one of the latest studies, the randomised phase III CHARTWEL (Continuous Hyperfractionated Accelerated Radiotherapy Weekend-less) trial (ARO 97-1) [7], showed no difference in outcome between 60 Gy in 40 fractions over 2.5 weeks (CHARTWEL) or 66 Gy in 33 fractions over 6.5 weeks. However, in comparison to previous trials the rate of squamous histology in the CHARTWEL trial was lower, which is the subgroup that seems to benefit most from accelerated RT [8].

For patients with early stage NSCLC who are medically inoperable a good option is hypofractionated/ stereotactic radiation therapy [9-12]. There is a clear benefit for a biological effective dose $>100$ Gy in NSCLC [13-15]. What about high-dose/fraction treatments for stage III NSCLC? There are some studies with dose-accelerated schedules, using doses between 45 and $60 \mathrm{~Gy}$ in 3-15 fractions with promising local control rates and acceptable toxicity [16-18]. While the results of ongoing randomised trials on hypofractionated radiotherapy have to be awaited, a recent meta-analysis has already confirmed the role of accelerated hyperfractionation resulting in an absolute benefit of $2.5 \%$ in overall survival (8.3-10.8\%) at 5 years [19].

\section{Radiochemotherapy}

Radiotherapy alone has demonstrated reasonable response rates for locally advanced NSCLC, however the outcomes were very poor $[20,21]$. The introduction of sequential radiochemotherapy has led to an increase of overall survival from approximately $5 \%$ to $10 \%$ at 5 years with the addition of chemotherapy [22-24]. With the implementation of concurrent radiochemotherapy this rate rose to $15 \%$ with an absolute survival benefit of $4.5 \%$ at 5 years [25].

Although concurrent radiochemotherapy is associated with improved overall survival when compared with sequential treatment [1,26-30] (table 1), the latter is associated with lower toxicity (less oesophagitis/ pneumonitis). Thus, concomitant treatment is the preferred strategy for fit patients but sequential chemo-radiotherapy may be applied in selected cases (e.g. the elderly or those with poor performance status) for whom a concomitant radiochemotherapy is not deemed feasible.

Several regimens have been established in combination with radiotherapy. Doublet chemotherapy results in better progression-free survival rates than concomitant single-agent chemotherapy [25]. Platinum-based chemotherapy regimens are a standard of treatment [27]. These include: cisplatin (Cis)/etoposide (Eto), Cis/vinorelbine, Cis/vindesine, Cis/mitomycine/vindesine, Cis/docetaxel, Cis/gemcitabine, carboplatin (Carbo)/paclitaxel, Carbo/irinotecan, Carbo/Eto [1, 28-40]. The 5-year overall survival for the mentioned regimens is around $15-20 \%$. Patient comorbidities may help guide the choice of agent. While overall survival seems to be similar with these, less haematological toxicity but a higher risk of radiation pneumonitis was observed with Carbo/paclitaxel when compared to Cis/Eto [41]. Pemetrexed (Pem)/Cis seems to have a survival benefit for patients with metastatic non-squamous NSCLC [42]; however, no clear advantages are reported in locally advanced disease. In the PROCLAIM study presented at the American Society of Clinical Oncology Annual Meeting in 2015, concurrent Pem+Cis arm did not improve OS versus Cis/Eto, but did have a better safety profile [43].

Effective novel chemotherapy agents or targeted therapies, such as cetuximab, bevacizumab, gefitinib or anti-PD-1 inhibitors have so far led to rather disappointing results in combination with radiotherapy and may even bear the risk of unexpected toxicities like fistula, oesophagitis and bleeding [44-47]. So far, there is not enough evidence to support their routine use in radiochemotherapy protocols.

\section{Planning}

After obtaining imaging a planning computed tomography (CT), the typical procedure is to define the gross tumour volume (GTV), which represents the macroscopic tumour. Based on several investigations $[48,49]$, including histological evaluation of microscopic extensions the clinical target volume (CTV) is 
TABLE 1 An overview of selected trials investigating sequential or concurrent radio-chemotherapy

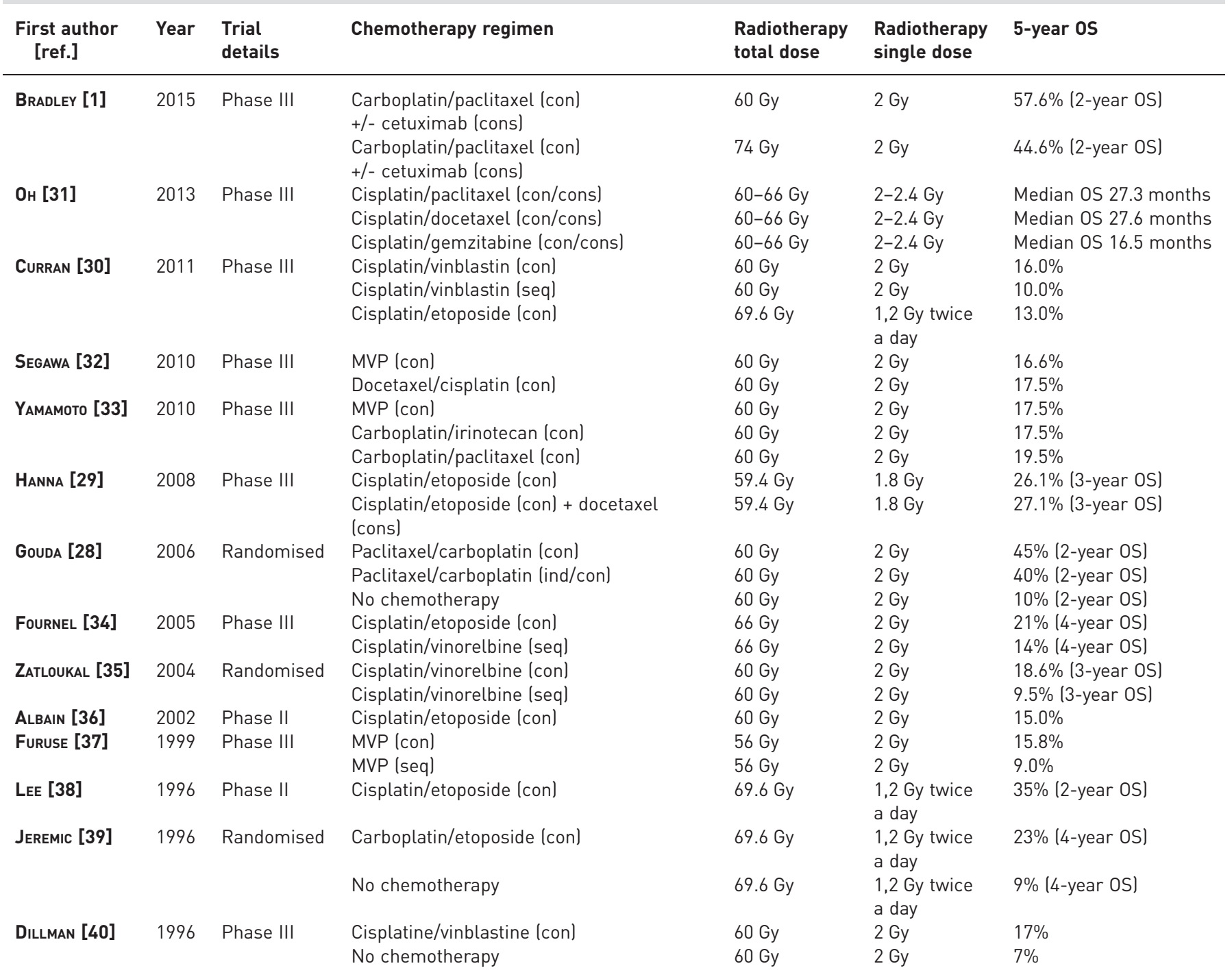

OS: overall survival; Con: concurrent; cons: consolidation; seq: sequential; MVP: mitomycin, vindesine, and cisplatin; ind: induction.

typically formed by adding 6-10 $\mathrm{mm}$ to the GTV in all directions (except where natural barriers would be expected, e.g. bone, pleura). Due to positioning and calculation inaccuracies, a further margin is added to create the planning target volume.

While imaging has generally improved and staging has become more precise, technological advancements have also helped in dealing with an obvious problem in radiotherapy for lung cancer: tumour movement. This has led the International Commission on Radiation Units to implement a new volume, internal target volume (ITV), which is used to account for tumour motion, primarily through breathing. Modern radiation oncology dedicated CT-scanners are capable of four-dimensional CTs, this means that imaging is acquired over different phases of the breathing cycle and the collected images are binned to create a "breathing" CT, which serves as a basis for the ITV. An alternative approach is to irradiate the CTV in a specific breathing phase (e.g. only inhalation or exhalation) using phased-gating or tracking, where small target volumes are irradiated and therefore an ITV is omitted.

Initially, mediastinal lymph nodes were irradiated electively, meaning they were irradiated beyond the involved lymph nodes. One of the first trials investigating this was performed by YuAN et al. [50]. This trial compared $74 \mathrm{~Gy}$ to only involved nodes (involved field irradiation) and compared it with $60 \mathrm{~Gy}$ to include elective nodal stations (elective nodal irradiation). Involved field irradiation was associated with 
lower rates of radiation-induced pneumonitis and improved local control when compared with prophylactic lymph node irradiation. Several other trials have confirmed this approach also demonstrating the rate of recurrence in elective nodal regions at $<5 \%$ [51-53]. However, nearly all evidence on this topic derives from the three-dimensional conformal radiotherapy era with a relevant proportion of unaffected mediastinum being treated by incidental therapeutic doses. Except the single-centre prospective evidence from Yuan et al. [50], all data derive from retrospective series or secondary analyses. Despite this, the concept of involved node radiotherapy has become standard for locally advanced NSCLC radiotherapy to date. Recently, new data on a higher rate of out-of-field recurrences after more conformal planning and intensity-modulated radiotherapy [54] have arisen, so that further analyses and the result of running prospective trials may again change our perception here.

Dose escalation has been discussed and investigated for years. While several phase I-II trials have demonstrated improvement of local control, hard evidence for dose escalation beyond 60 Gy was lacking. The Radiation Therapy Oncology Group (RTOG) 0617 trial tested a dose escalation of 74 Gy versus 60 Gy. Surprising to many, the higher-dose arm was not associated with improved survival at 1 year but rather showed a contrary trend and the dose escalation arms were closed based on interim analysis [55]. Despite several doubts [56] about the causes involved in this result, the current standard of care is a radiation dose of 60-66 Gy and further dose escalation is still regarded as being experimental. This is also supported by the recent guidelines of the American Society for Therapeutic Radiation Oncology [57]. In many aspects, they are similar to the recommendations of the European Organisation for Research and Treatment of Cancer [58].

Thanks to modern treatment planning systems, it is possible to calculate the healthy tissue (organs at risk) doses in a respective radiotherapy plan. For decades, a consensus-based paper by EmAMI et al. [59] served as a pivot to predict tolerability of treatment. Due to an evidence-based pooled analysis of RTOG, the QUANTEC [60] project produced data that is currently used to predict the side effects of radiotherapy and the tolerability of evaluated treatment plans. Toxicities of radiotherapy typically include the organs that are irradiated due to their adjacency to the tumour. These include primarily organs of the thorax, specifically: the spinal cord [61], the lungs [62], the heart [63] and the oesophagus [64]. The typical constraints that are usually aimed for are: volume of organ receiving at least 20 Gy less than $30-35 \%$ and a mean lung dose of under 20-23 Gy. The volumes and doses in most analyses have considered the total lung volume, however individual (ipsi- and contralateral) lung doses have been also demonstrated to be predictive of radiation pneumonitis $[5,65]$. When the appropriate criteria are taken into account the risk of side effects can be reduced and treatments become better tolerated.

\section{Conclusion}

Radiochemotherapy has an established role in the treatment of stage III lung cancer. Modern radiotherapy techniques may contribute to reducing toxicities. Concurrent chemotherapy is typically a platin-based doublet therapy. Whenever possible, concurrent radiochemotherapy is preferred, whereas for individual patients a sequential approach might be feasible.

\section{References}

1 Bradley JD, Paulus R, Komaki R, et al. Standard-dose versus high-dose conformal radiotherapy with concurrent and consolidation carboplatin plus paclitaxel with or without cetuximab for patients with stage IIIA or IIIB non-small-cell lung cancer (RTOG 0617): a randomised, two-by-two factorial phase 3 study. Lancet Oncol 2015; 16: 187-199.

2 Putora PM, Früh M, Kern L. The place of radiotherapy in the palliative management of NSCLC. Breathe 2011; 8: 134-143.

3 Riquet M, Mordant P, Fabre-Guillevin E, et al. Long-term survival with surgery as part of a multimodality approach for N3 lung cancer. Eur J Cardiothorac Surg 2013; 44: 1117-1122.

4 Robinson LA, Ruckdeschel JC, Wagner H Jr, et al. Treatment of non-small cell lung cancer-stage IIIA: ACCP evidence-based clinical practice guidelines. Chest 2007; 132: Suppl 3, 243S-265S.

5 Cox JD, Azarnia N, Byhardt RW, et al. A randomized phase I/II trial of hyperfractionated radiation therapy with total doses of 60.0 Gy to 79.2 Gy: possible survival benefit with greater than or equal to 69.6 Gy in favorable patients with Radiation Therapy Oncology Group stage III non-small-cell lung carcinoma: report of Radiation Therapy Oncology Group 83-11. J Clin Oncol 1990; 8: 1543-1555.

6 Saunders M, Dische S, Barrett A, et al. Continuous, hyperfractionated, accelerated radiotherapy (CHART) versus conventional radiotherapy in non-small cell lung cancer: mature data from the randomised multicentre trial. CHART Steering committee. Radiother Oncol 1999; 52: 137-148.

7 Baumann M, Herrmann T, Koch R, et al. Final results of the randomized phase III CHARTWEL-trial (ARO 97-1) comparing hyperfractionated-accelerated versus conventionally fractionated radiotherapy in non-small cell lung cancer (NSCLC). Radiother Oncol 2011; 100: 76-85.

8 Saunders M, Dische S, Barrett A, et al. Continuous hyperfractionated accelerated radiotherapy (CHART) versus conventional radiotherapy in non-small-cell lung cancer: a randomised multicentre trial. CHART Steering Committee. Lancet 1997; 350: 161-165.

9 Fakiris AJ, McGarry RC, Yiannoutsos CT, et al. Stereotactic body radiation therapy for early-stage non-small-cell lung carcinoma: four-year results of a prospective phase II study. Int J Radiat Oncol Biol Phys 2009; 75: 677-682. 
10 Timmerman R, Paulus R, Galvin J, et al. Stereotactic body radiation therapy for inoperable early stage lung cancer. JAMA 2010; 303: 1070-1076.

11 Baumann P, Nyman J, Hoyer M, et al. Outcome in a prospective phase II trial of medically inoperable stage I non-small-cell lung cancer patients treated with stereotactic body radiotherapy. J Clin Oncol 2009; 27: 3290-3296.

12 Lagerwaard FJ, Haasbeek CJ, Smit EF, et al. Outcomes of risk-adapted fractionated stereotactic radiotherapy for stage I non-small-cell lung cancer. Int J Radiat Oncol Biol Phys 2008; 70: 685-692.

13 Onishi H, Shirato H, Nagata Y, et al. Hypofractionated stereotactic radiotherapy (HypoFXSRT) for stage I non-small cell lung cancer: updated results of 257 patients in a Japanese multi-institutional study. J Thorac Oncol 2007; 2: Suppl. 3, S94-S100.

14 Kong FM, Ten Haken RK, Schipper MJ, et al. High-dose radiation improved local tumor control and overall survival in patients with inoperable/unresectable non-small-cell lung cancer: long-term results of a radiation dose escalation study. Int J Radiat Oncol Biol Phys 2005; 63: 324-333.

15 Kong FM, Zhao J, Wang J, et al. Radiation dose effect in locally advanced non-small cell lung cancer. J Thorac Dis 2014; 6: 336-347.

16 Gomez DR, et al. Phase 1 study of dose escalation in hypofractionated proton beam therapy for non-small cell lung cancer. Int J Radiat Oncol Biol Phys 2013; 86: 665-670.

17 Amini A, Lin SH, Wei C, et al. Accelerated hypofractionated radiation therapy compared to conventionally fractionated radiation therapy for the treatment of inoperable non-small cell lung cancer. Radiat Oncol 2012; 7: 33.

18 Cannon DM, Mehta MP, Adkison JB, et al. Dose-limiting toxicity after hypofractionated dose-escalated radiotherapy in non-small-cell lung cancer. J Clin Oncol 2013; 31: 4343-4348.

19 Mauguen A, Le Péchoux C, Saunders MI, et al. Hyperfractionated or accelerated radiotherapy in lung cancer: an individual patient data meta-analysis. J Clin Oncol 2012; 30: 2788-2797.

20 Johnson DH, Einhorn LH, Bartolucci A, et al. Thoracic radiotherapy does not prolong survival in patients with locally advanced, unresectable non-small cell lung cancer. Ann Intern Med 1990; 113: 33-38.

21 Perez CA, Pajak TF, Rubin P, et al. Long-term observations of the patterns of failure in patients with unresectable non-oat cell carcinoma of the lung treated with definitive radiotherapy report by the radiation therapy oncology group. Cancer 1987; 59: 1874-1881.

22 Dillman RO, Seagren SL, Propert KJ, et al. A randomized trial of induction chemotherapy plus high-dose radiation versus radiation alone in stage III non-small-cell lung cancer. $N$ Engl J Med 1990; 323: 940-945.

23 O’Rourke N, Roqué I Figuls M, Farré Bernadó N, et al. Concurrent chemoradiotherapy in non-small cell lung cancer. Cochrane Database Syst Rev 2010; 6: CD002140.

24 Rowell NP, O’Rourke NP. Concurrent chemoradiotherapy in non-small cell lung cancer. Cochrane Database Syst Rev 2004; 4: CD002140.

25 Aupérin A, Le Péchoux C, Rolland E, et al. Meta-analysis of concomitant versus sequential radiochemotherapy in locally advanced non-small-cell lung cancer. J Clin Oncol 2010; 28: 2181-2190.

26 Belani CP, Wang W, Johnson DH, et al. Phase III study of the Eastern Cooperative Oncology Group (ECOG 2597): induction chemotherapy followed by either standard thoracic radiotherapy or hyperfractionated accelerated radiotherapy for patients with unresectable stage IIIA and B non-small-cell lung cancer. J Clin Oncol 2005; 23: 3760-3767.

27 Provencio M, Isla D, Sánchez A, et al. Inoperable stage III non-small cell lung cancer: current treatment and role of vinorelbine. J Thorac Dis 2011; 3: 197-204.

28 Gouda YS, Kohail HM, Eldeeb NA, et al. Randomized study of concurrent carboplatin, paclitaxel, and radiotherapy with or without prior induction chemotherapy in patients with locally advanced non-small cell lung cancer. J Egypt Natl Canc Inst 2006; 18: 73-81.

29 Hanna N, Neubauer M, Yiannoutsos C, et al. Phase III study of cisplatin, etoposide, and concurrent chest radiation with or without consolidation docetaxel in patients with inoperable stage III non-small-cell lung cancer: the Hoosier Oncology Group and U.S. Oncology. J Clin Oncol 2008; 26: 5755-5760.

30 Curran WJ Jr, Paulus R, Langer CJ, et al. Sequential versus concurrent chemoradiation for stage III non-small cell lung cancer: randomized phase III trial RTOG 9410. J Natl Cancer Inst 2011; 103: 1452-1460.

31 Oh IJ, Kim KS, Kim YC, et al. A phase III concurrent chemoradiotherapy trial with cisplatin and paclitaxel or docetaxel or gemcitabine in unresectable non-small cell lung cancer: KASLC 0401. Cancer Chemother Pharmacol 2013; 72: 1247-1254.

32 Segawa $\mathrm{Y}$, Kiura $\mathrm{K}$, Takigawa $\mathrm{N}$, et al. Phase III trial comparing docetaxel and cisplatin combination chemotherapy with mitomycin, vindesine, and cisplatin combination chemotherapy with concurrent thoracic radiotherapy in locally advanced non-small-cell lung cancer: OLCSG 0007. J Clin Oncol 2010; 28: 3299-3306.

33 Yamamoto N, Nakagawa K, Nishimura Y, et al. Phase III study comparing second- and third-generation regimens with concurrent thoracic radiotherapy in patients with unresectable stage III non-small-cell lung cancer: West Japan Thoracic Oncology Group WJTOG0105. J Clin Oncol 2010; 28: 3739-3745.

34 Fournel P, Robinet G, Thomas P, et al. Randomized phase III trial of sequential chemoradiotherapy compared with concurrent chemoradiotherapy in locally advanced non-small-cell lung cancer: Groupe Lyon-Saint-Etienne d'Oncologie Thoracique-Groupe Francais de Pneumo-Cancerologie NPC 95-01 Study. J Clin Oncol 2005; 23: 5910-5917.

35 Zatloukal P, Petruzelka L, Zemanova M, et al. Concurrent versus sequential chemoradiotherapy with cisplatin and vinorelbine in locally advanced non-small cell lung cancer: a randomized study. Lung Cancer 2004; 46: 87-98.

36 Albain KS, Crowley JJ, Turrisi AT 3rd, et al. Concurrent cisplatin, etoposide, and chest radiotherapy in pathologic stage IIIB non-small-cell lung cancer: a Southwest Oncology Group phase II study, SWOG 9019. J Clin Oncol 2002; 20: 3454-3460.

37 Furuse K, Fukuoka M, Kawahara M, et al. Phase III study of concurrent versus sequential thoracic radiotherapy in combination with mitomycin, vindesine, and cisplatin in unresectable stage III non-small-cell lung cancer. J Clin Oncol 1999; 17: 2692-2699.

38 Lee JS, Scott C, Komaki R, et al. Concurrent chemoradiation therapy with oral etoposide and cisplatin for locally advanced inoperable non-small-cell lung cancer: radiation therapy oncology group protocol 91-06. J Clin Oncol 1996; 14: 1055-1064.

39 Jeremic B, Shibamoto Y, Acimovic L, et al. Hyperfractionated radiation therapy with or without concurrent low-dose daily carboplatin/etoposide for stage III non-small-cell lung cancer: a randomized study. J Clin Oncol 1996; 14: 1065-1070. 
Dillman RO, Herndon J, Seagren SL, et al. Improved survival in stage III non-small-cell lung cancer: seven-year follow-up of cancer and leukemia group B (CALGB) 8433 trial. J Natl Cancer Inst 1996; 88: 1210-1215.

41 Liew MS, Sia J, Starmans MH, et al. Comparison of toxicity and outcomes of concurrent radiotherapy with carboplatin/paclitaxel or cisplatin/etoposide in stage III non-small cell lung cancer. Cancer Med 2013; 2: 916-924.

42 Scagliotti G, Hanna N, Fossella F, et al. The differential efficacy of pemetrexed according to NSCLC histology: a review of two Phase III studies. Oncologist 2009; 14: 253-263.

43 Senan S, Brade AM, Wang L, et al. Final overall survival (OS) results of the phase III PROCLAIM trial: Pemetrexed (Pem), cisplatin (Cis) or etoposide (Eto), Cis plus thoracic radiation therapy (TRT) followed by consolidation cytotoxic chemotherapy (CTX) in locally advanced nonsquamous non-small cell lung cancer (nsNSCLC). J Clin Oncol 2015; 33: suppl, abstr 7506.

44 Spigel DR, Greco FA, Meluch AA, et al. Phase I/II trial of preoperative oxaliplatin, docetaxel, and capecitabine with concurrent radiation therapy in localized carcinoma of the esophagus or gastroesophageal junction. $J$ Clin Oncol 2010; 28: 2213-2219.

45 Spigel DR, Hainsworth JD, Yardley DA, et al. Tracheoesophageal fistula formation in patients with lung cancer treated with chemoradiation and bevacizumab. J Clin Oncol 2010; 28: 43-48.

46 Socinski MA, Stinchcombe TE, Moore DT, et al. Incorporating bevacizumab and erlotinib in the combined-modality treatment of stage III non-small-cell lung cancer: results of a phase I/II trial. J Clin Oncol 2012; 30: 3953-3959.

47 Blumenschein GR Jr, Paulus R, Curran WJ, et al. Phase II study of cetuximab in combination with chemoradiation in patients with stage IIIA/B non-small-cell lung cancer: RTOG 0324. J Clin Oncol 2011; 29: 2312-2318.

48 Giraud P, Antoine M, Larrouy A, et al. Evaluation of microscopic tumor extension in non-small-cell lung cancer for three-dimensional conformal radiotherapy planning. Int J Radiat Oncol Biol Phys 2000; 48: 1015-1024.

49 Grills IS, Fitch DL, Goldstein NS, et al. Clinicopathologic analysis of microscopic extension in lung adenocarcinoma: defining clinical target volume for radiotherapy. Int J Radiat Oncol Biol Phys 2007; 69: 334-341.

50 Yuan S, Sun X, Li M, et al. A randomized study of involved-field irradiation versus elective nodal irradiation in combination with concurrent chemotherapy for inoperable stage III nonsmall cell lung cancer. Am J Clin Oncol 2007; 30: 239-244.

51 Senan S, Burgers S, Samson MJ, et al. Can elective nodal irradiation be omitted in stage III non-small-cell lung cancer? Analysis of recurrences in a phase II study of induction chemotherapy and involved-field radiotherapy. Int J Radiat Oncol Biol Phys 2002; 54: 999-1006.

52 Fernandes AT, Shen J, Finlay J, et al. Elective nodal irradiation (ENI) versus involved field radiotherapy (IFRT) for locally advanced non-small cell lung cancer (NSCLC): a comparative analysis of toxicities and clinical outcomes. Radiother Oncol 2010; 95: 178-184.

53 Sulman EP, Komaki R, Klopp AH, et al. Exclusion of elective nodal irradiation is associated with minimal elective nodal failure in non-small cell lung cancer. Radiat Oncol 2009; 4: 5

54 Rajpara RS, Schreibmann E, Fox T, et al. Locoregional tumor failure after definitive radiation for patients with stage III non-small cell lung cancer. Radiat Oncol 2014; 9: 187.

55 Bradley JD, Paulus R, Komaki R, et al. A randomized phase III comparison of standard-dose (60 Gy) versus high-dose $(74 \mathrm{~Gy})$ conformal chemoradiotherapy with or without cetuximab for stage III non-small cell lung cancer: results on radiation dose in RTOG 0617. J Clin Oncol 2013; 31: suppl, abstr 7501.

56 Cox JD. Are the results of RTOG 0617 mysterious? Int I Radiat Oncol Biol Phys 2012; 82: 1042-1044.

57 Rodrigues G, Choy H, Bradley J, et al. Definitive radiation therapy in locally advanced non-small cell lung cancer: Executive summary of an American Society for Radiation Oncology (ASTRO) evidence-based clinical practice guideline. Pract Radiat Oncol 2015; 5: 141-148.

58 De Ruysscher D, Faivre-Finn C, Nestle U, et al. European Organisation for Research and Treatment of Cancer recommendations for planning and delivery of high-dose, high-precision radiotherapy for lung cancer. $J$ Clin Oncol 2010; 28: 5301-5310.

59 Emami B, Lyman J, Brown A, et al. Tolerance of normal tissue to therapeutic irradiation. Int J Radiat Oncol Biol Phys 1991; 21: 109-122.

60 Marks LB, Bentzen SM, Deasy JO, et al. Radiation dose-volume effects in the lung. Int J Radiat Oncol Biol Phys 2010; 76: Suppl. 3, S70-S76.

61 Kirkpatrick JP, van der Kogel AJ, Schultheiss TE. Radiation dose-volume effects in the spinal cord. Int J Radiat Oncol Biol Phys 2010; 76: Suppl. 3, S42-S49.

62 Palma DA, Senan S, Tsujino K, et al. Predicting radiation pneumonitis after chemoradiation therapy for lung cancer: an international individual patient data meta-analysis. Int J Radiat Oncol Biol Phys 2013; 85: 444-450.

63 Gagliardi G, Constine LS, Moiseenko V, et al. Radiation dose-volume effects in the heart. Int J Radiat Oncol Biol Phys 2010; 76: Suppl. 3, S77-S85.

64 Palma DA, Senan S, Oberije C, et al. Predicting esophagitis after chemoradiation therapy for non-small cell lung cancer: an individual patient data meta-analysis. Int J Radiat Oncol Biol Phys 2013; 87: 690-696.

65 Ramella S, Trodella L, Mineo TC, et al. Adding ipsilateral V 20 and V 30 to conventional dosimetric constraints predicts radiation pneumonitis in stage IIIA-B NSCLC treated with combined-modality therapy. Int $J$ Radiat Oncol Biol Phys 2010; 76: 110-115. 